\title{
Management of refractory ischemic priapism: current perspectives
}

This article was published in the following Dove Press journal:

Research and Reports in Urology

29 August 2017

Number of times this article has been viewed

\author{
Marco Capece' \\ Arianna Gillo² \\ Andrea Cocci ${ }^{3}$ \\ Giulio Garaffa' \\ Massimiliano Timpano 4 \\ Marco Falcone ${ }^{4}$ \\ 'The Institute of Urology, University \\ College of London Hospital (UCLH), \\ London, UK; ' 2 Department of Urology, \\ "Umberto Parini" Hospital, Aosta, \\ ${ }^{3}$ Department of Urology, Careggi \\ Hospital, Firenze, ${ }^{4}$ Department of \\ Urology, University of Turin, Città \\ della Salute e della Scienza, Turin, Italy
}

Correspondence: Marco Falcone

Department of Urology, University of

Turin, Città della Salute e della Scienza,

Corso Bramante 88, Torino 10100, Italy

Tel +39349710 6866

Email marco.falcone@androteam.it
Objectives: The aim of the present manuscript is to review the current literature on priapism, focusing on the state-of-the-art knowledge of both the diagnosis and the treatment of the refractory ischemic priapism (IP).

Methods: Pubmed and EMBASE search engines were used to search for words "priapism", "refractory priapism", "penile prosthesis", "diagnosis priapism", "priapism treatment", "penile fibrosis", "priapism therapy". All the studies were carefully examined by the authors and then included in the review.

Results: First-line treatment involves ejaculation, physical exercise and cold shower followed by corporal blood aspiration and injection of $\alpha$-adrenoceptor agonists. Subsequently, a distal or proximal shunt may be considered. If none of the treatment is effective or the priapism episode lasts $>48$ hours penile prosthesis implantation could be the only option to solve the priapism and treat the ongoing erectile dysfunction.

Conclusion: The management of IP is to achieve detumescence of persistent penile erection and to preserve erectile function after resolution of the priapic episode. On the other hand, penile fibrosis and following shortening should be prevented. Early penile prosthesis implantation in patients with refractory IP is able to solve both the priapic episode and prevent the otherwise certain penile shortening. Penile prosthesis implantation is the actual gold standard of care in cases of refractory IP. Keywords: priapism, ischemic priapism, penile fibrosis, penile prosthesis, shunt

\section{Objectives}

The aim of the present manuscript is to review the current literature on priapism, focusing on the state-of-the-art knowledge of both the diagnosis and the treatment of the refractory ischemic priapism (IP).

\section{Acquisition of evidence}

A review has been conducted using Pubmed and EMBASE as search engines. The Medline search using the words "priapism" as a mesh term with "refractory", "penile prosthesis", "diagnosis", "treatment", "fibrosis", "therapy", was carried out in February 2017. All the publications were examined by all the authors and disagreements on the conclusions were resolved by discussion among them.

\section{Synthesis of evidence Definition and classification}

Priapism is a prolonged erection that persists longer than 4 hours, irrespective of any sexual stimulation and beyond the reaching of an orgasm. The condition can be 
classified into three main categories: non-ischemic priapism (NIP - also known as "arterial" or "high-flow"), the much more frightening IP-(also known as "veno-occlusive" or "low-flow") and finally, a third rare variant, the stuttering priapism ("recurrent" or "intermittent") characterized by repetitive and painful episodes of IP. ${ }^{1,2}$

IP is the most common type of priapism, accounting for up to $95 \%$ of all priapic events. ${ }^{3}$ The pathological mechanism underlying this phenomenon is an obstruction of the penile venous outflow, which leads to a stasis of hypoxic blood within the corpus cavernosum akin to a proper compartment syndrome leading to hypoxia, hypercapnia, acidosis and glucopenia. ${ }^{4,5}$

There are many underlying causes of IP; however the most common are hematological diseases, drugs, intracorporal injection of vasoactive drugs, neurological disease and malignancy. ${ }^{3,6-9}$

It is a rare condition with overall incidence of 1.5 cases per 100,000 person-years; however it is an important urologic condition as it could be a symptom hiding a hemoglobinopathy such as sickle cell disease, thalassemia or hematological malignancies, which cause an obliteration of the small emissary veins in the subtunical space and lead to the ischemic episode. $^{4-7,10}$

IP is considered a proper medical emergency as the acidotic and hypoxic environment progressively results in significant decrease in contractility and apoptosis. ${ }^{11}$ During early stages of IP ( $<12$ hours) the $\mathrm{pO}_{2}$ falls as the closed compartment prevents replenishment of stagnant blood with freshly oxygenated blood and the ultrastructure of the erectile tissue happens to change with thickening and interstitial edema. Cavernosal muscle necrosis starts becoming evident after 24 hours, hence fibroblasts recruitment begins. At this point, the risk of penile fibrosis and complete erectile dysfunction is $>90 \%$. After 72 hours, complete erectile dysfunction occurs as smooth muscle necrosis is inevitable. ${ }^{12,13}$

From a molecular point of view, IP is characterized by a decrease in phosphodiesterase type 5 (PDE5) and RhoA/Rho kinase, and increased levels of adenosine. Indeed, the RhoA/Rho kinase signal transduction pathway is the predominant vasoconstrictor pathway in the penis that maintains the organ in a flaccid state. This pathway regulates penile flaccidity by modulating the eNOS and activating the ROCK1 and ROCK2, two isoforms of Rhoassociated coiled-coil forming protein serine/threonine kinase. Dysregulated Rho/ROCK signaling contributes to the pathophysiology of priapism. ${ }^{12,14}$
Moreover, the presence of acidosis, glucopenia and hypoxia contribute to the cavernosal smooth muscle dysfunction. $^{5}$

If left untreated, unless the rare occurrence of a malignant infiltration of the corpora occurs, the degree of tumescence tends to subside spontaneously within and the necrotic cavernosal tissue progresses into an extended fibrosis, resulting in severe erectile dysfunction refractory to any medical treatment and eventually in a shortened penis. ${ }^{13}$

\section{Diagnosis}

The diagnosis of IP is based on a detailed past medical history, genital clinical examination (as the pain is a classical finding in IP), radiological imaging and blood gas analysis. We underline the necessity of a urine toxicology examination, a hematological screening and an abdominal/pelvis scan, before asserting the idiopathic cause of the IP.

Color Doppler Ultrasound (DUS) of the penis certainly plays a role in assessing the presence of any flow in the cavernosal arteries to differentiate IP from NIP. In the case of IP, DUS shows a peculiar pattern of absent or reduced flow within the cavernosal arteries, while in NIP, the DUS of the penis often shows a normal or increased flow and irregular flow from the artery to the cavernosal body at the site of injury, suggestive of an arterial-lacunar fistula. However, the most reliable investigation to distinguish between IP and NIP is corporal blood gas analysis, which will typically show ischemic, venous blood with $\mathrm{pO}_{2}<30 \mathrm{mmHg}$ and $\mathrm{pCO}_{2}$ $>60 \mathrm{mmHg}$, and $\mathrm{pH}<7.25$ in cases of low-flow priapism. ${ }^{1,2}$

\section{First-line treatments}

Once the diagnosis of IP has been confirmed, the initial management involves ejaculation, physical exercise and cold shower to stimulate the noradrenergic system, leading to smooth muscle contraction and eventually inducement of detumescence. ${ }^{1,2}$ If a conservative approach fails, corporal blood irrigation followed by an instillation of $\alpha$-agonists directly into the corpus cavernosum is considered as the most valuable option. The drainage of the corporal ischemic blood has been evaluated as being effective in $>36 \%$ of IP episodes. ${ }^{3}$ According to the recent European Association of Urology guidelines, a variety of agents can be considered for intracavernosal injection: phenylephrine, etilephrine and adrenaline. ${ }^{1}$ Phenylephrine should be diluted in normal saline to a concentration of $100-500 \mu \mathrm{g} / \mathrm{mL}$ and $1 \mathrm{~mL}$ given every 3-5 minutes, up to a maximum dosage of $1 \mathrm{mg}$, while adrenalin can be diluted to $1 / 100.000 \mathrm{mg} / \mathrm{mL}$ and $2 \mathrm{~mL}$ given for a maximum of five times throughout a period of 20 minutes. ${ }^{1}$ 
Corporal blood aspiration and intracorporeal injection of $\alpha$-adrenergic agents are recommended if the priapic event lasts $>24-36$ hours, although these patients are very unlikely to respond due to smooth muscle necrosis.

\section{Surgical interventions}

If corporal blood aspiration and injections of $\alpha$-adrenergic agonists fail, the second-line treatment consists of a penile shunt surgery. Distal shunts should be attempted before proximal shunts, because they are easier to perform and have low incidence of complications.

The Winter shunt is the most common percutaneous procedure. With this intervention, a fistula between the corpus spongiosum and the corpora cavernosa is created. The shunt can be created also with an open procedure. Al Ghorab's shunt, for example, consists of an open excision of the circular cone segment of the distal tunica albuginea and subsequent skin closure. ${ }^{1}$ In any case, the choice of a specific approach is left to the surgeon's experience.

In the event of an IP lasting $>36$ hours, shunt surgery is unlikely to be effective. In these types of cases, early penile prosthesis (PP) implantation can be considered. ${ }^{1}$ The shunt surgery is even less effective if the duration of priapism is $>48$ hours. In these cases, the success rate is extremely low in contrast to the incidence of severe erectile dysfunction (ED) in which the success rate proved to be extremely high. ${ }^{15-19}$

\section{Early penile prosthesis implantation}

When none of the above treatments are effective or after 48 hours of duration of the IP, an early insertion of PP is an option. ${ }^{1}$ In this group of patients, indeed, the natural course of the disturb brings to a severe ED associated with a significant shortening of the shaft secondary to a diffuse corporal fibrosis, located particularly in the distal corpora. An early implantation before the development of a dense fibrosis has been demonstrated to give more satisfactory results, preserving the length of the shaft as well as reducing the risk related to a difficult penile implantation in a fibrotic penis. In fact, it is no doubt true that recent reports have underlined that immediate PP implantation in these patients can resolve the painful erection, guarantee adequate long-term rigidity for sexual penetration and prevent the otherwise inevitable penile shortening. ${ }^{13,20,21-31}$

A potential overtreatment in patients with no evidence of necrosis in the cavernosal smooth muscle is one of the risks associated with this approach. Therefore, correct timing of the surgery is essential. Preoperative penile magnetic resonance imaging (MRI) and cavernosal smooth muscle biopsies during the shunt procedure, or frozen sections during the implantation surgery are mandatory to confirm the presence of necrosis and to assist the surgeon in the eventual decision to proceed with the insertion of an implant. ${ }^{20} \mathrm{MRI}$ of the penis has been demonstrated to reach a sensitivity of nearly $100 \%$ when used to detect the presence of necrosis of the cavernosal smooth muscle. ${ }^{32}$ Thus, the potential risk of overtreatment is easily overcome by performing either a penile MRI or a cavernosal biopsy during the shunt procedure.

\section{Surgical technique}

An early penile prosthesis implantation is usually approached by a single transverse penoscrotal incision, away from the oedematous penile skin or previous incisions. Intravenous (IV) antibiotic prophylaxis is mandatory, and we suggested an IV administration for 3 days postoperatively, which should then be switched to oral for another 4 days. Both corpora are carefully isolated and longitudinally incised. A biopsy of the endocavernosal tissue is performed and when possible a frozen section examination is requested. The corpora are usually easily dilated with Hegar's or Brook's dilators, as the fibrosis has not yet occurred. Extensive corporal washout with antibiotic (rifampicin and gentamicin) is performed. Finally, the PP is inserted. The risk of postoperative hematoma formation can be minimized with the use of a close circuit drain and with the application of a compressive dressing (mummy-wrap). ${ }^{20}$

\section{Early versus delayed penile prosthesis implantation}

If the IP episode is treated conservatively, the use of a vacuum pump associated with pde 5 inhibitors can be proposed as an option to recover the erectile function. However, if necrosis of the corporal smooth muscle has already occurred, rehabilitation will be ineffective and the patient will develop a refractory ED with fibrosis and shortening of the penis. ${ }^{13,20}$ The dense fibrosis involving the penis after refractory IP damages the distal part of the corpora, while the proximal corpora are usually spared. On the other hand, refractory IP patients not responding to aspirations, pharmacological treatments or shunt surgery are destined to a PP implantation if they want to continue an active sexual life. The accurate timing of the setting of irreversible changes in the corpora cavernosa is still unknown and it represents the main open issue in the management of patients with a delayed IP presentation. The most common complication of early implant is the higher risk of infection $(6 \%-7 \%)$ compared with virgin implantation. Clearly, this is related to the previous aspiration 
or percutaneous shunt, which creates a link between the skin and the corpora cavernosa, increasing the risk of introducing bacteria in a sterile environment. Nevertheless, the edema of the cavernosal tissues reduces the penetration of the antibiotic. The longer the procedure is delayed, the greater the risk corporal fibrosis will be found. The exact timing of the formation of a penile fibrosis after a IP episode is still under debate, even if some recent evidences suggested that a straightforward implantation is possible 4 weeks after the IP episode. ${ }^{13,20,26,29}$

The second open issue is the choice of the type of implant (malleable vs inflatable). Most authors chose to insert a malleable penile prosthesis as a first-choice implant because the compartment syndrome secondary to IP tends to be a fibrotic process of the tissue that surrounds the cylinders of the implant. The malleable implant, which is semi-rigid by definition, protects itself from any form of contracture or penile deformity. On the other hand, a risk of distal erosion sharply higher than with inflatable implants (up to 6\%) must be considered in patients who have undergone percutaneous distal shunt. ${ }^{13-24,33-35}$ Inflatable PP can be considered as an option, but the implant must be cycled daily after 1 week to prevent the risks aforementioned. ${ }^{36}$

Inserting a PP in patients with severe corporal fibrosis represents a real challenge, with high risk of complications such as urethral injuries, distal or lateral perforation, cylinders crossover and infection. In these cases, the use of a blunt dilation by Hegar's or Brook's dilators is usually not adequate to dilate the corpora, and Rossello or Uramix cavernotomes are often needed to excise fibrotic tissue to make space for accommodating the cylinders (the concept of "cavernosal drilling"). Adopting this technique, the infection rate is $6.3 \%$, and the revision rate at 1 year is $13 \% .^{36-38}$

Moreover, accessory incision, most commonly a subcoronal one associated with a distal corporotomy, is often required to create a cavernosal channel under direct vision. Alternatively, in an attempt to minimize the dissection, the transverse penoscrotal incision can be extended distally along the rafe down to the coronal sulcus in " $\mathrm{T}$ "-shaped fashion to obtain a wider corpora on the ventral aspect. ${ }^{36}$ As previously stated, the surgery in these selected cases can be extremely challenging, complication rates can be as high as $65 \%$, with up to $30 \%$ of patients experiencing infection of the device, and an overall prosthesis survival of only $50 \%$ at 1 year. ${ }^{36}$ Nevertheless, whichever technique is used, once the shortening of the penis has happened there is no way to restore it, although some authors advocate the implantation of downsized inflatable devices that would act as tissue expanders and to upsize them after 6-12 months. ${ }^{39}$

\section{Conclusions}

Nowadays, the goal of the management of IP is to achieve detumescence of persistent penile erection and to preserve erectile function after resolution of the priapic episode. Cavernosal tissue damage in IP is time related, even if the specific timing of irreversible damage is still unknown. Conservative measures and aspiration, with or without intracorporeal instillation of $\alpha$-adrenergic agonists, are usually successful in the early stages, but become useless after 48-72 hours when the necrosis of the smooth muscle has occurred. Percutaneous shunt surgery remains debatable, as the lack of response to aspiration and instillation of $\alpha$-adrenergic agonists indicates that irreversible changes in the cavernosal smooth muscle are likely to have already occurred. Therefore, shunt surgery may relieve the painful erection but will not prevent the formation of fibrosis and the consequent erectile dysfunction, which is not the actual aim of the treatment.

In this scenario, early penile prosthesis implantation in patients with refractory IP is able to solve the priapic episode and prevent the otherwise penile shortening. Regarding the erectile function, when the fibrosis occurs, the chances of recovering are inconsistent, and the penile implant could be the only solution to this issue.

Although complication rates after immediate insertion of PP in refractory IP are higher than in virgin cases, they are still lower compared to delayed PP implantation after severe corporal fibrosis. Clearly, if one knew that smooth muscle necrosis had already occurred at the time of the IP episode, then any attempt to perform shunt surgery should be avoided at the first instance to reduce the complication rate after the implant.

In conclusion, PP implantation is the actual gold standard of care in cases of refractory IP, and if performed within a few weeks from the priapic episode avoids penile shortening, surgical complication and patient dissatisfaction.

\section{Disclosure}

The authors report no conflicts of interest in this work.

\section{References}

1. Salonia A, Eardley I, Giuliano F, et al. European Association of Urology guidelines on priapism. Eur Urol. 2014;65(2):480-489.

2. Montague DK, Jarow J, Broderick GA, et al; Members of the Erectile Dysfunction Guideline Update Panel; Americal Urological Association. American urological association guideline on the management of priapism. J Urol. 2003;170(4 Pt 1):1318-1324. 
3. Broderick GA, Kadioglu A, Bivalacqua TJ, Ghanem H, Nehra A, Shamloul R. Priapism: pathogenesis, epidemiology, and management. $J$ Sex Med. 2010;7(1 Pt 2):476-500.

4. Bivalacqua TJ, Musicki B, Kutlu O, Burnett AL. New insights into the pathophysiology of sickle cell disease-associated priapism. J Sex Med. 2012;9(1):79-87.

5. Lagoda G, Sezen SF, Cabrini MR, Musicki B, Burnett AL. Molecular analysis of erection regulatory factors in sickle cell disease associated priapism in the human penis. $J$ Urol. 2013;189(2):762-768.

6. Eland IA, Van der Lei J, Stricker BH, Sturkenboom MJ. Incidence of priapism in the general population. Urology. 2001;57(5):970-972.

7. Furtado PS, Costa MP, Ribeiro do Prado Valladares F, et al. The prevalence of priapism in children and adolescents with sickle cell disease in Brazil. Int J Hematol 2012;95(6):648-651.

8. Lin YH, Kim JJ, Stein NB, Khera M. Malignant priapism secondary to metastatic prostate cancer: a case report and review of literature. Rev Urol. 2011;13(2):90-94.

9. Porst $\mathrm{H}$. The rationale for prostaglandin $\mathrm{E} 1$ in erectile failure: a survey of worldwide experience. J Urol. 1996;155(3):802-815.

10. Lionnet F, Hammoudi N, Stojanovic KS, et al. Hemoglobin sickle cell disease complications: a clinical study of 179 cases. Haematologica. 2012;97(8):1136-1141.

11. Broderick GA, Gordon D, Hypolite J, Levin RM. Anoxia and corporal smooth muscle dysfunction: a model for ischemic priapism. $J$ Urol. 1994;151(1):259-262.

12. Spycher MA, Hauri D. The ultrastucture of the erectile tissue in priapism. J Urol. 1986;135(1):142-147.

13. Zacharakis E, Garaffa G, Raheem AA, Christopher AN, Muneer A, Ralph DJ. Penile prosthesis insertion in patients with refractory ischaemic priapism: early vs delayed implantation. BJU Int. 2014;114(4):576-581.

14. Anele UA, Morrison BF, Burnett AL. Molecular pathophysiology of priapism: emerging targets. Curr Drug Targets 2015;16(5):474-483

15. Muruve N, Hosking DH. Intracorporeal phenylephrine in the treatment of priapism. J Urol. 1996;155(1):141-143.

16. Muneer A, Minhas S, Freeman A, Kumar P, Ralph DJ. Investigating the effects of high-dose phenylephrine in the management of prolonged ischaemic priapism. J Sex Med. 2008;5(9):2152-2159.

17. Moon DG, Lee DS, Kim JJ. Altered contractile response of penis under hypoxia with metabolic acidosis. Int J Impot Res. 1999;11(5):265-271.

18. Mantadakis E, Ewalt DH, Cavender JD, Rogers ZR, Buchanan G. Outpatient penile aspiration and epinephrine irrigation for young patients with sickle cell anemia and prolonged priapism. Blood 2000;95(1):78-82.

19. Burnett AL. Surgical management of ischemic priapism. J Sex Med. 2012;9(1):114-120.

20. Ralph DJ, Garaffa G, Muneer A, et al. The immediate insertion of a penile prosthesis for acute ischaemic priapism. Eur Urol. 2009;56(6):1033-1038.

21. Faddan AA, Aksenov AV, Naumann CM, Jünemann KP, Osmonov DK. Semi-rigid penile prosthesis as a salvage management of idiopathic ischemic stuttering priapism. Res Rep Urol. 2015;7:137-141.
22. Monga M, Broderick GA, Hellstrom WJ. Priapism in sickle cell disease: the case for early implantation of the penile prosthesis. Eur Urol. 1996;30(1):54-59.

23. Montague DK. Sexual dysfunction: immediate penile prosthesis for acute ischemic priapism. Nat Rev Urol. 2010;7(4):187-188.

24. Rees RW, Kalsi J, Minhas S, Peters J, Kell P, Ralph DJ. The management of low-flow priapism with the immediate insertion of a penile prosthesis. BJU Int. 2002;90(9):893-897.

25. Salem EA, El Aasser O. Management of ischemic priapism by penile prosthesis insertion: prevention of distal erosion. $J$ Urol. 2010;183(6):2300-2303.

26. Sedigh O, Rolle L, Negro CL, et al. Early insertion of inflatable prosthesis for intractable ischemic priapism: our experience and review of the literature. Int J Impot Res. 2011;23(4):158-164.

27. Sundaram CP, Fernandes ET, Ercole C, et al. Management of refractory priapism with penile prostheses. Br J Urol. 1997;79(4):659.

28. Tausch TJ, Evans LA, Morey AF. Immediate insertion of a semirigid penile prosthesis for refractory ischemic priapism. Mil Med. 2007;172(11):1211-1212.

29. Tausch TJ, Mauck R, Zhao LC, Morey AF. Penile prosthesis insertion for acute priapism. Urol Clin North Am. 2013;40(3):421-425.

30. Tausch TJ, Zausch LC, Morey AF, et al. Malleable penile prosthesis is a cost-effective treatment for refractory ischemic priapism. $J$ Sex Med. 2015;12(3):824-826.

31. Upadhyay J, Shekarriz B, Dhabuwala CB. Penile implant for intractable priapism associated with sickle cell disease. Urology 1998;51(4):638-639.

32. Ralph DJ, Borley NC, Allen C, et al. The use of high-resolution magnetic resonance imaging in the management of patients presenting with priapism. BJU Int. 2010;106(11):1714-1718.

33. Nixon RG, O'Connor JL, Milam DF. Efficacy of shunt surgery for refractory low flow priapism: a report on the incidence of failed detumescence and erectile dysfunction. J Urol. 2003;170(3):883-886.

34. Segal RL, Readal N, Pierorazio PM, Burnett AL, Bivalacqua TJ. Corporal Burnett "Snake" surgical maneuver for the treatment of ischemic priapism: long-term follow-up. J Urol. 2013;189(3):1025-1029.

35. Zacharakis E., Raheem AA., Freeman A, et al. The efficacy of the T-shunt procedure and intracavernous tunneling (snake maneuver) for refractory ischemic priapism. J Urol. 2014;191(1):164-168.

36. Martínez-Salamanca JI, Mueller A, Moncada I, Carballido J, Mulhall JP. Penile prosthesis surgery in patients with corporal fibrosis: a state of the art review. J Sex Med. 2011;8(7):1880-1889.

37. Wilson SK. Reimplantation of inflatable penile prosthesis into scarred corporeal bodies. Int J Impot Res. 2003;15(Suppl 5):S125-S128.

38. Mulcahy JJ. Surgical management of penile prosthesis complications. Int J Impot Res. 2000;12(Suppl 4):S108-S111.

39. Wilson SK, Delk JR 2nd, Mulcahy JJ, Cleves M, Salem EA. Upsizing of inflatable penile implant cylinders in patients with corporal fibrosis. J Sex Med. 2006;3(4):736-742.
Research and Reports in Urology

\section{Publish your work in this journal}

Research and Reports in Urology is an international, peer-reviewed, open access journal publishing original research, reports, editorials, reviews and commentaries on all aspects of adult and pediatric urology in the clinic and laboratory including the following topics: Pathology, pathophysiology of urological disease; Investigation and treatment of urological disease; Pharmacology of drugs used for the treatment of urological disease. The manuscript management system is completely online and includes a very quick and fair peer-review system, which is all easy to use. Visit http://www.dovepress.com/testimonials.php to read real quotes from published authors. 